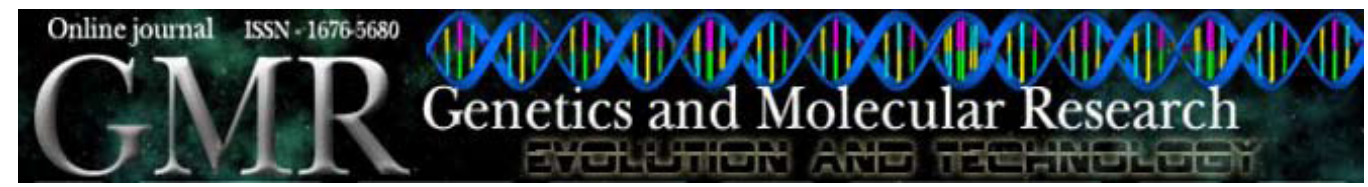

\title{
Effects of low-energy argon ion implantation on the dynamic organization of the actin cytoskeleton during maize pollen germination
}

\author{
F. Deng ${ }^{1,3 *}$, S.W. Zhu ${ }^{1 *}$, L.J. Wu ${ }^{2}$ and B.J. Cheng ${ }^{1}$ \\ ${ }^{1}$ Anhui Provincial Key Laboratory of Crop Biology, \\ Anhui Agricultural University, Hefei, Anhui, China \\ ${ }^{2}$ Institute of Plasma Physics, Chinese Academy of Sciences, \\ Hefei, Anhui, China \\ ${ }^{3}$ Department of Chemistry and Materials, Chaohu College, \\ Chaohu, Anhui, China \\ *These authors contributed equally to this study. \\ Corresponding author: B. Cheng \\ E-mail: beijiucheng@ahau.edu.cn \\ Genet. Mol. Res. 9 (2): 785-796 (2010) \\ Received January 12, 2010 \\ Accepted February 12, 2010 \\ Published April 27, 2010 \\ DOI 10.4238/vol9-2gmr768
}

\begin{abstract}
The relationship between pollen germination and the dynamic organization of the actin cytoskeleton during pollen germination is a central theme in plant reproductive biology research. Maize (Zea mays) pollen grains were implanted with 30 $\mathrm{keV}$ argon ion $\left(\mathrm{Ar}^{+}\right)$beams at doses ranging from $0.78 \times 10^{15}$ to $13 \times 10^{15}$ ions $/ \mathrm{cm}^{2}$. The effects of low-energy ion implantation on pollen germination viability and the dynamic organization of the actin cytoskeleton during pollen germination were studied using confocal laser scanning microscopy. Maize pollen germination rate increased remarkably with $\mathrm{Ar}^{+}$dose, in the range from $3.9 \times 10^{15}$ to $6.5 \times 10^{15} \mathrm{ions} / \mathrm{cm}^{2}$; the germination rate peaked at an $\mathrm{Ar}^{+}$dose of $5.2 \times 10^{15}$ ions $/ \mathrm{cm}^{2}$. When the implantation dose exceeded 7.8 $\times 10^{15}$ ions $/ \mathrm{cm}^{2}$, the rate of pollen germination decreased sharply. The actin filaments assembled in pollen grains implanted with $5.2 \times$ $10^{15}$ ions $/ \mathrm{cm}^{2} \mathrm{Ar}^{+}$much earlier than in controls. The actin filaments organized as longer parallel bundles and extended into the emerg-
\end{abstract}


ing pollen tube in treated pollen grains, while they formed random and loose fine bundles and were gathered at the pollen aperture in the control. The reorganization of actin cytoskeleton in the pollen implanted with $9.1 \times 10^{15}$ ions $/ \mathrm{cm}^{2} \mathrm{Ar}^{+}$was slower than in controls. There was a positive correlation between pollen germination and the dynamic organization of the actin cytoskeleton during pollen germination. Ion implantation into pollen did not cause changes in the polarization of actin filaments and organelle dynamics in the pollen tubes. The effects of $\mathrm{Ar}^{+}$implantation on pollen germination could be mediated by changes in the polymerization and rearrangement of actin polymers.

Key words: Maize pollen; Low-energy ion implantation; Pollen germination; Actin cytoskeleton

\section{INTRODUCTION}

The pollen grain is the male gametophyte of seed plants, in which pollen tube growth is the process by which flowering plants transport the male gamete to the ovule. Previous studies have found that the actin cytoskeleton is a key element for the germination and the elongation of pollen tubes (Steer and Steer, 1989; Cheung, 1995; FrankinTong, 1999; Wheeler et al., 2001). During the germination of pollen, the organization and architecture of actin filaments are dramatically altered (Ikeda et al., 1997; Yang, 1999; Camacho and Malho, 2003). In the pollen tube shaft, actin filaments are organized in bundles that are parallel or slightly helical to the tube's longitudinal axis. These actin filaments, together with myosin, generate the cytoplasmic streaming for transport of organelles and Golgi-driven secretory vesicles, and such cytoplasmic streaming frequently exhibits a "reverse fountain" pattern with the streaming occurring acropetally along the edge or side of tubes (Taylor and Hepler, 1997; Franklin-Tong et al., 1997). Although the arrays of actin cytoskeleton during pollen tube growth have already been described, the precise functions of actin arrays and how the dynamic organization of actin arrays takes place are not yet fully understood.

As a new source of mutation, low-energy ion beam implantation techniques developed very quickly because of their unique mutation mechanism and biological effects. Nowadays, these techniques have been applied to many research fields, such as health care, life's origin and evolution, and radiobiological effect of the environment (Yu and Shao, 1994; Lu et al., 1995; Wu et al., 1999). However, most of the studies have focused on their effects at the physiological and genetic level, and at present, little is known about these effects at the subcellular level (Mascarenhas, 1993; Wei et al., 1996; Yu, 1999). Combined with their relative ease of experimental manipulation, these features make the pollen grain a good recipient material for the study of the interaction of lowenergy ion beams and complex organisms at the cellular level.

The aim of this study was to investigate the effects of low-energy argon ion $\left(\mathrm{Ar}^{+}\right)$ implantation on maize pollen germination and the dynamic organization of the actin cytoskeleton during pollen germination, which not only provides a new method for studying 
the development control mechanism of pollen polar formation and pollen tube growth, but also provides clues for further research on the cellular mechanism of biological effects of low-energy ion implantation.

\section{MATERIAL AND METHODS}

\section{Plant material}

The source of maize (Zea mays L.) pollen was the cultivated maize inbred line 478, which is stored in the Key Laboratory of Crop Biology, Anhui Agricultural University. The pollen grains were freshly collected from plants at 10:00 am for use.

\section{Ion implantation}

Implantation was performed with an implanter (LZD900) at the Key Laboratory of Ion Beam Bioengineering (LIBB), Chinese Academy of Sciences (CAS). The fresh pollen grains were scattered evenly on glass dishes with a diameter of $9 \mathrm{~cm}$ and placed perpendicular to the ion beams in a vacuum sample chamber $\left(2.0 \times 10^{-2} \mathrm{~Pa}\right)$. The pollen grains were implanted with $30 \mathrm{keV}$ argon ion beams in pulse mode. The doses used in the present study were 0 (control), $0.78,1.3,2.6,3.9,5.2,6.5,7.8,9.1,10.4$, and $13 \times 10^{15} \mathrm{ions} / \mathrm{cm}^{2}$.

\section{Pollen germination}

Pollen grains were placed on Petri dishes on BK medium (Brewbaker, 1963) (16\% sucrose, $100 \mathrm{mg} / \mathrm{L} \mathrm{H}_{3} \mathrm{BO}_{3}, 200 \mathrm{mg} / \mathrm{L} \mathrm{MgSO}_{4}, 300 \mathrm{mg} / \mathrm{L} \mathrm{Ca}\left(\mathrm{NO}_{3}\right)^{2}, 100 \mathrm{mg} / \mathrm{L} \mathrm{KNO}$, $\mathrm{pH}$ 6.3) in the dark at $26^{\circ} \mathrm{C}$. A pollen grain was classified as germinated when the pollen tube length was equal to at least half of the pollen grain diameter. At least 100 samples were taken randomly to determine germination rate, germination vigor (germination rate per unit time) and the length of pollen tubes in each experiment.

\section{Fluorescence labeling of F-actin}

Germinated maize pollen was fixed in a freshly prepared solution of $3.7 \%$ paraformaldehyde in $50 \mathrm{mM}$ PIPES buffer, $\mathrm{pH} 6.9$, for $1 \mathrm{~h}$. After washing three times in $50 \mathrm{mM}$ PIPES buffer, the samples were incubated in $3.3 \mu \mathrm{M}$ TRITC-phalloidin (Sigma, USA), and shaken at $60 \mathrm{rpm}$ at $27^{\circ} \mathrm{C}$ in the dark for $2 \mathrm{~h}$. They were then mounted on slides in $50 \%$ glycerol containing Vectashield (Vector, USA).

\section{Confocal scanning microscopy and image analysis}

Pollen germination and pollen tube growth was observed under a fluorescence microscope (Olympus BH-2, Germany). Confocal laser microscopy (Leica TCS SP2) was employed to obtain the image of the actin cytoskeleton in pollen grains and pollen tubes using illumination from the 568 line of a $\mathrm{Kr} / \mathrm{Ar}$ laser. Images were analyzed using the standard software supplied with a microscope. 


\section{RESULTS}

\section{Effects of $\mathrm{Ar}^{+}$implantation on maize pollen germination}

\section{Effects of implanted Ar ${ }^{+}$dose on pollen germination rate and germination vigor}

Investigation of the effects of $\mathrm{Ar}^{+}$implantation on pollen germination is very important to reveal the relationship between the dynamic organization of actin cytoskeleton during pollen germination and variation of pollen germination rate. Although vacuum treatment of the target chamber is required for implanting $\mathrm{Ar}^{+}$into the pollens, the results show that vacuum treatment had no significant effect on the fertility of maize pollen. As shown in Figure 1, the pollen germination rates slightly decreased at the initial dose of 0.78 to $2.6 \times 10^{15} \mathrm{ions} / \mathrm{cm}^{2}$ and significantly increased with $\mathrm{Ar}^{+}$implantation at a dose ranging from 3.9 to $6.5 \times 10^{15} \mathrm{ions} / \mathrm{cm}^{2}$, in which the germination rate peaked at a dose of $5.2 \times 10^{15} \mathrm{ions} / \mathrm{cm}^{2}$. However, when the implantation dose exceeded $7.8 \times 10^{15}$ ions $/ \mathrm{cm}^{2}$, pollen germination tended to decrease sharply.

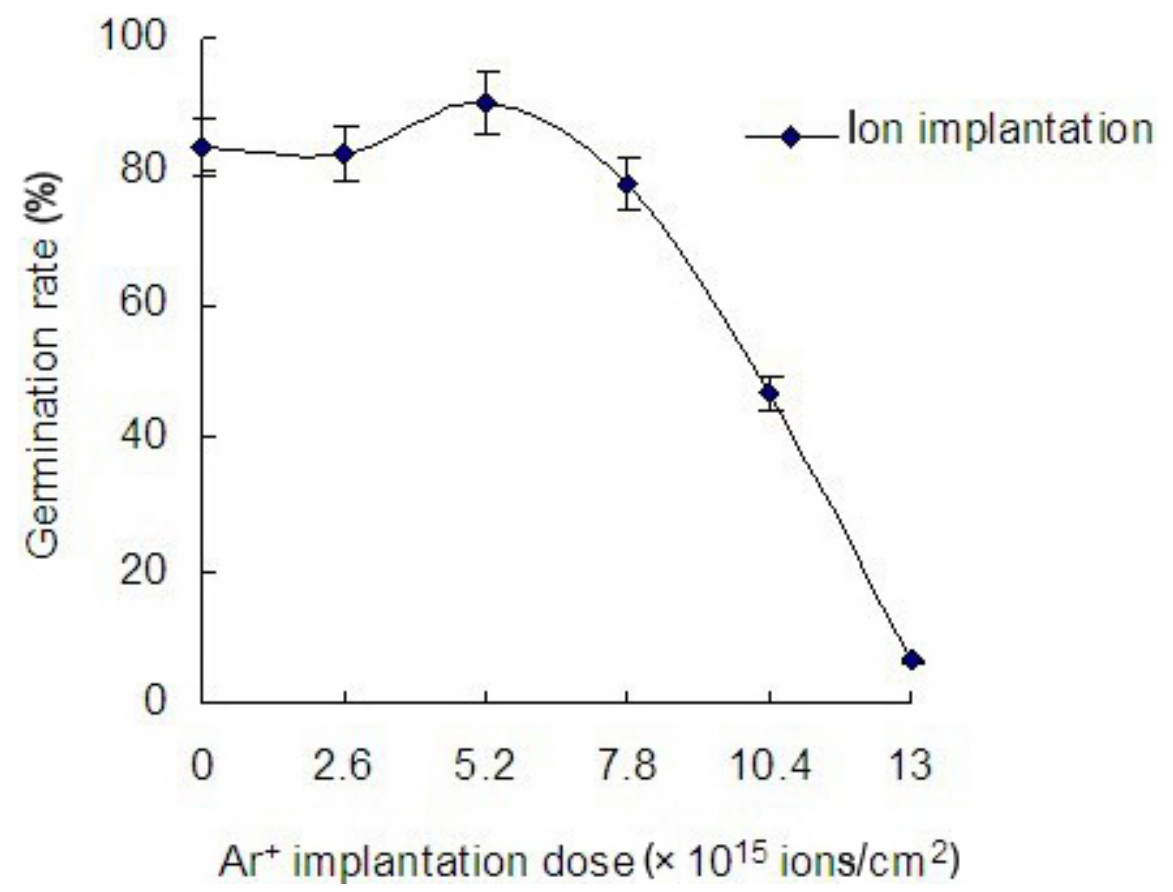

Figure 1. The effect of $\mathrm{Ar}^{+}$implantation on pollen germination rate.

As shown in Figure 2, pollen germination vigor was the highest from pollen hydration to $30 \mathrm{~min}$, decreased afterwards, remained stable during 60-120 min, and tended to vanish after 120 min of germination. For instance, the germination vigor of the pollen implanted by $5.2 \times$ $10^{15}$ ions $/ \mathrm{cm}^{2} \mathrm{Ar}^{+}$was higher than that of the control within 30 min after germination, and 60 min later, it declined and tended to be the same as the control. In contrast, within $60 \mathrm{~min}$, the 
germination vigor of the pollen implanted by $9.1 \times 10^{15}$ ions $/ \mathrm{cm}^{2} \mathrm{Ar}^{+}$was remarkably lower than that of the control, especially in the first $30 \mathrm{~min}$. These results reveal that ion implantation just affects the initiation of pollen germination, where low-dose ion implantation could stimulate pollen germination, while the high-dose injection significantly inhibits pollen germination.

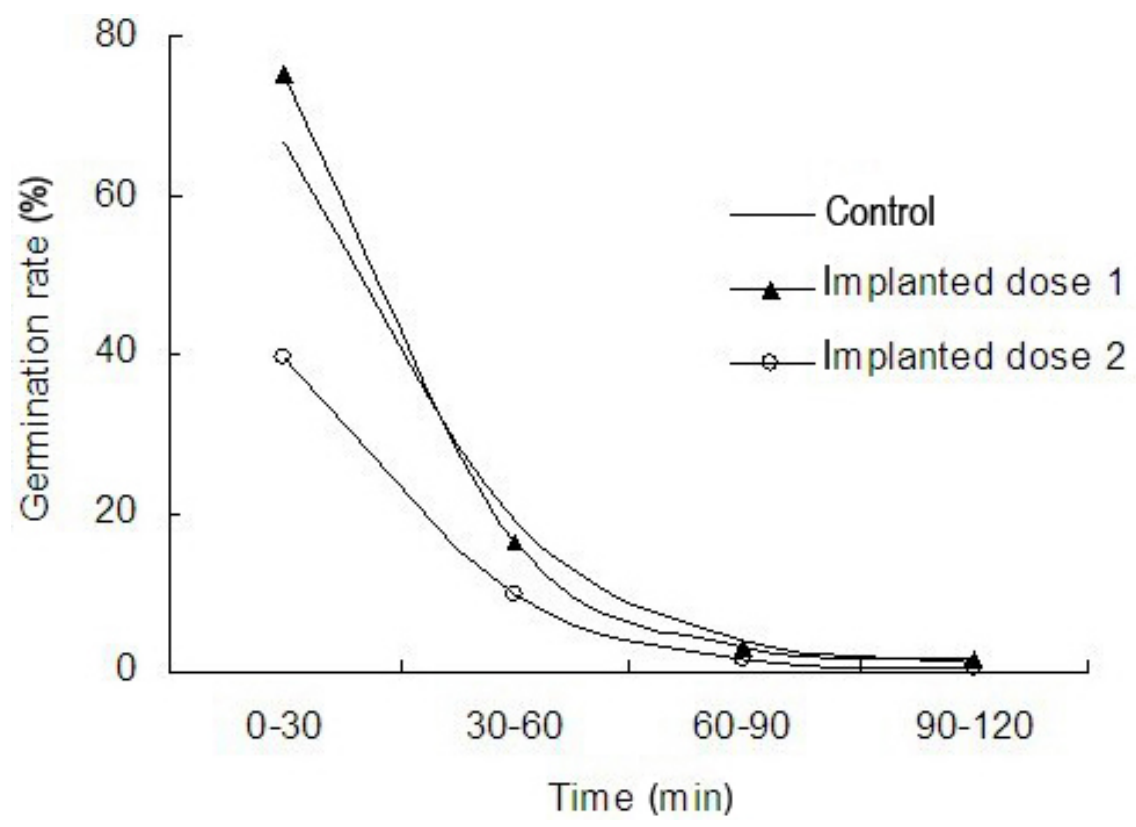

Figure 2. The effect of $\mathrm{Ar}^{+}$implantation on pollen vigor. Dose $1=5.2 \times 10^{15} \mathrm{ions} / \mathrm{cm}^{2}$; Dose $2=9.1 \times 10^{15} \mathrm{ions} / \mathrm{cm}^{2}$.

\section{Effects of $\mathrm{Ar}^{+}$implantation on the growth of pollen tube}

The effects of $\mathrm{Ar}^{+}$implantation on the growth of the pollen tube are shown in Table 1. After $180 \mathrm{~min}$ of in vitro germination, the average length of pollen tubes implanted by 5.2 $\times 10^{15}$ ions $/ \mathrm{cm}^{2} \mathrm{Ar}^{+}$reached $831.1 \pm 15.9 \mu \mathrm{m}$, which was substantially greater than that of the control. However, the average length of pollen tubes implanted by $9.1 \times 10^{15}$ ions $/ \mathrm{cm}^{2} \mathrm{Ar}^{+}$ $[181.0 \pm 9.9 \mu \mathrm{m}]$ showed an opposite result. There was a distinct correlation between pollen tube growth and pollen germination rate.

Table 1. The effect of $\mathrm{Ar}^{+}$implantation on polen tube growth.

\begin{tabular}{lcccr}
\hline Time $(\mathrm{min})$ & \multicolumn{4}{c}{ Pollen tube length $(\mu \mathrm{m})$} \\
\cline { 2 - 5 } & Control & $1.3 \times 10^{15}$ ions $/ \mathrm{cm}^{2}$ & $5.2 \times 10^{15}$ ions $/ \mathrm{cm}^{2}$ & $9.1 \times 10^{15}$ ions $/ \mathrm{cm}^{2}$ \\
\hline 30 & $154.2 \pm 5.4$ & $110.2 \pm 4.6$ & $222.0 \pm 6.3$ & $82.1 \pm 2.4$ \\
60 & $301.2 \pm 7.6$ & $237.5 \pm 5.3$ & $393.1 \pm 7.1$ & $118.0 \pm 5.6$ \\
90 & $390.1 \pm 8.1$ & $301.2 \pm 7.5$ & $546.9 \pm 8.2$ & $139.3 \pm 6.8$ \\
120 & $499.6 \pm 11.4$ & $382.0 \pm 10.8$ & $780.6 \pm 10.4$ & $167.5 \pm 7.6$ \\
150 & $583.4 \pm 12.3$ & $439.7 \pm 11.7$ & $831.1 \pm 15.9$ & $179.6 \pm 8.1$ \\
180 & $619.0 \pm 17.5$ & $454.1 \pm 14.2$ & $181.0 \pm 9.9$ \\
\hline
\end{tabular}


After $\mathrm{Ar}^{+}$implantation, most of the pollen tubes that were elongated in treated pollen grains showed no significant difference compared to the control pollen tube (Figure 3A), but we also observed some abnormal pollen tubes: pollen tube wall became rough and irregular, losing normally smooth structure (Figure 3B); 2 or 3 pollen tubes germinated from pollen aperture, and both of them were able to elongate (Figure 3C); pollen tube branched from the tip (Figure 3D). Although the morphology of these pollen tubes were different from the control, the cytoplasm of these abnormally growing tubes exhibited a vigorous streaming motion, which also appeared as a "reverse fountain" streaming pattern like in untreated pollen tube. This result indicates that the effects of ion implantation on the pollen did not change the original pattern of cytoplasmic streaming and organelle movements in the pollen tube.

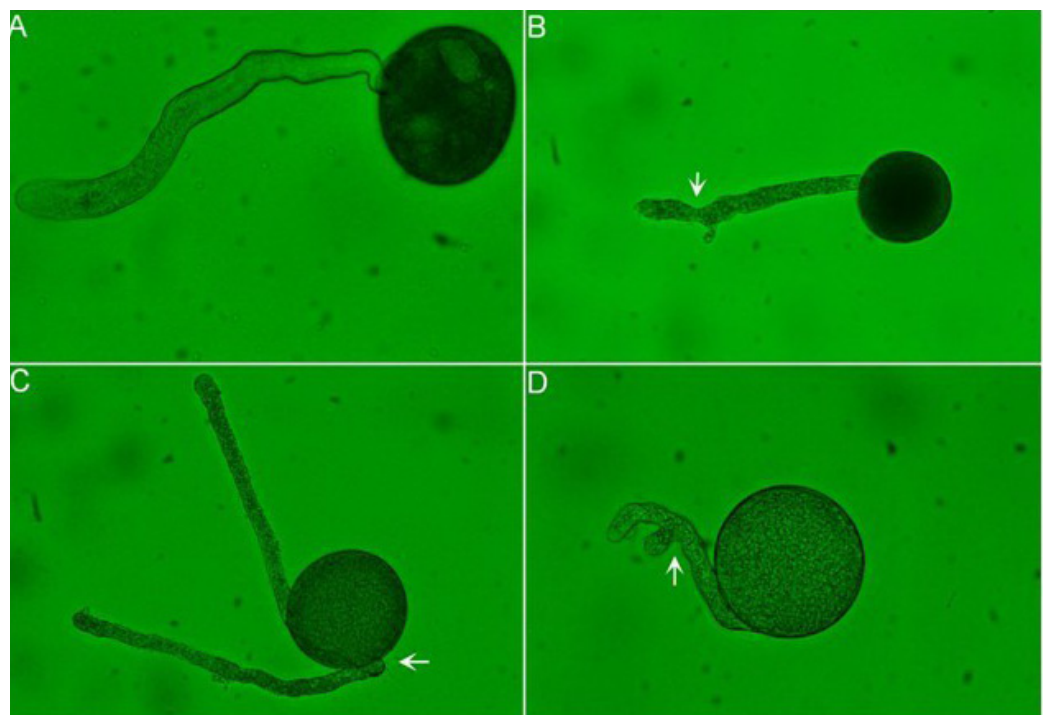

Figure 3. The effect of $\mathrm{Ar}^{+}$implantation on pollen tube morphology. A. Normal pollen tube. B. Irregular pollen tube wall. Arrow shows that pollen tube became thinner in diameter and reorientation. C. Two tubes arising from aperture (arrow: aperture). D. Branched pollen tube (arrow: the branch point).

\section{Effects of $\mathrm{Ar}^{+}$implantation on the dynamic organization of the actin cytoskeleton}

It has been reported that pollen germination involves three successive processes: hydration, polarity formation and pollen tube elongation, among which the dynamic organization of the actin cytoskeleton plays a major role. In the present study, two $\mathrm{Ar}^{+}$doses of 5.2 and $9.1 \times$ $10^{15}$ ions $/ \mathrm{cm}^{2}$, which were proved to be pollen germination promoting and pollen germination repressing, were adopted to implant maize pollen for detecting the distribution of the actin cytoskeleton in pollen grains and pollen tubes during pollen germination by fluorescence labeling.

\section{Effects of $\mathrm{Ar}^{+}$implantation on the reorganization of the actin cytoskeleton during pollen germination}

With TRITC-phalloidin labeling, the confocal laser scanning microscope showed actin cytoskeleton in germinating maize pollen grain and pollen tube. When the pollen began 
to hydrate in the medium, no actin filaments were found either in the control pollen or in the treated pollen (Figure 4A,B). Actins were packed in fusiform or spicule forms in the pollen implanted with $5.2 \times 10^{15}$ ions $/ \mathrm{cm}^{2} \mathrm{Ar}^{+}$(Figure 4B), and such structures were the storage form of actin, which showed that monomeric actin (G-actin) is starting to assemble into filamentous actin (F-actin) (Heslop-Harrison et al., 1986). However, such structure was not found in the control (Figure 4A) and $9.1 \times 10^{15}$ ions $/ \mathrm{cm}^{2} \mathrm{Ar}^{+}$implanted pollen (Figure 4C). The results indicate that the assembly of F-actin in the pollen implanted by $5.2 \times 10^{15} \mathrm{ions} / \mathrm{cm}^{2} \mathrm{Ar}^{+}$starts much earlier than that in the control pollen.
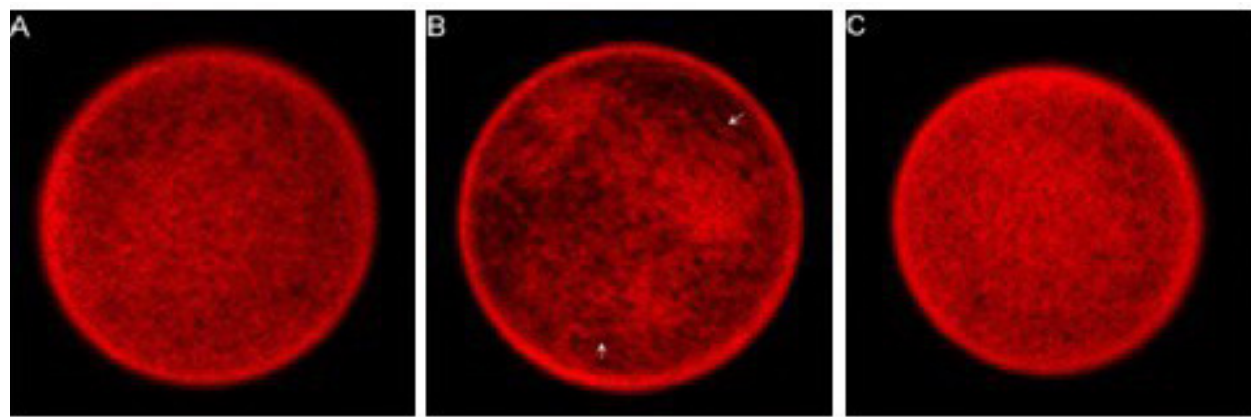

Figure 4. Confocal images of F-actin in hydrating pollen grain. A. Control. B. F-actin in pollen implanted with 5.2 $\times 10^{15}$ ions $/ \mathrm{cm}^{2} \mathrm{Ar}^{+}$(arrows: short actin fibers). C. Pollen implanted with $9.1 \times 10^{15}$ ions $/ \mathrm{cm}^{2} \mathrm{Ar}^{+}$.

After hydration of pollen for 10 min, the obvious F-actin structure was observed in the pollen grains. The actin filaments formed cross-linked fine networks in the control pollen (Figure 5A), but in the $5.2 \times 10^{15} \mathrm{ions} / \mathrm{cm}^{2} \mathrm{Ar}^{+}$implantation-treated pollens, the actin filaments were organized into continuous long bundles (Figure 5B). However, only few short and thick actin filaments were found in $9.1 \times 10^{15}$ ions $/ \mathrm{cm}^{2} \mathrm{Ar}^{+}$implantation-treated pollens (Figure 5C). The results indicated that the actin cytoskeleton in the pollens implanted by $5.2 \times 10^{15}$ ions/ $\mathrm{cm}^{2} \mathrm{Ar}^{+}$reorganized much earlier than that in the control pollen, but the reorganization of actin cytoskeleton in the pollen implanted with $9.1 \times 10^{15}$ ions $/ \mathrm{cm}^{2} \mathrm{Ar}^{+}$was comparatively slower than that in the control pollen.
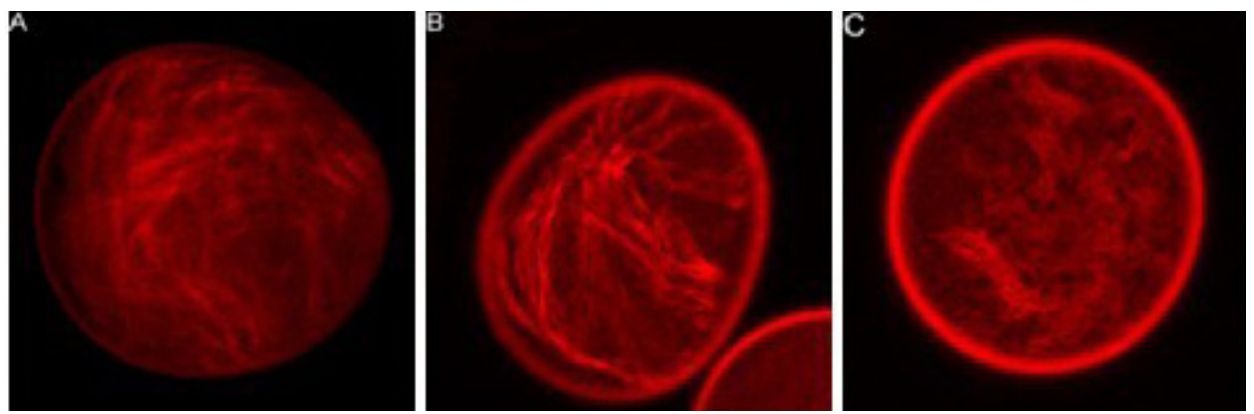

Figure 5. Confocal images of the actin filaments in pollen hydrated for $10 \mathrm{~min}$. A. The actin filament networks in control. B. Long actin bundles formed in $5.2 \times 10^{15} \mathrm{ions} / \mathrm{cm}^{2} \mathrm{Ar}^{+}$implanted pollen. C. Actin filaments just emerging in $9.1 \times 10^{15}$ ions $/ \mathrm{cm}^{2} \mathrm{Ar}^{+}$implanted pollen. 
The polarization of actin filaments initiates with the emergence of the pollen tube. When the pollen tube just began to elongate, it was observed that in the control pollen, the actin filaments formed random and loose fine bundles and were gathered at the pollen aperture (Figure 6A). In the $5.2 \times 10^{15}$ ions $/ \mathrm{cm}^{2} \mathrm{Ar}^{+}$implantation-treated pollen, dense actin filaments organized as longer parallel bundles and extended into the emerging pollen tube (Figure 6B). However, the actin filaments in the $9.1 \times 10^{15}$ ions $/ \mathrm{cm}^{2} \mathrm{Ar}^{+}$ implantation-treated pollen did not have the same polarity distribution as the former (Figure 6C).
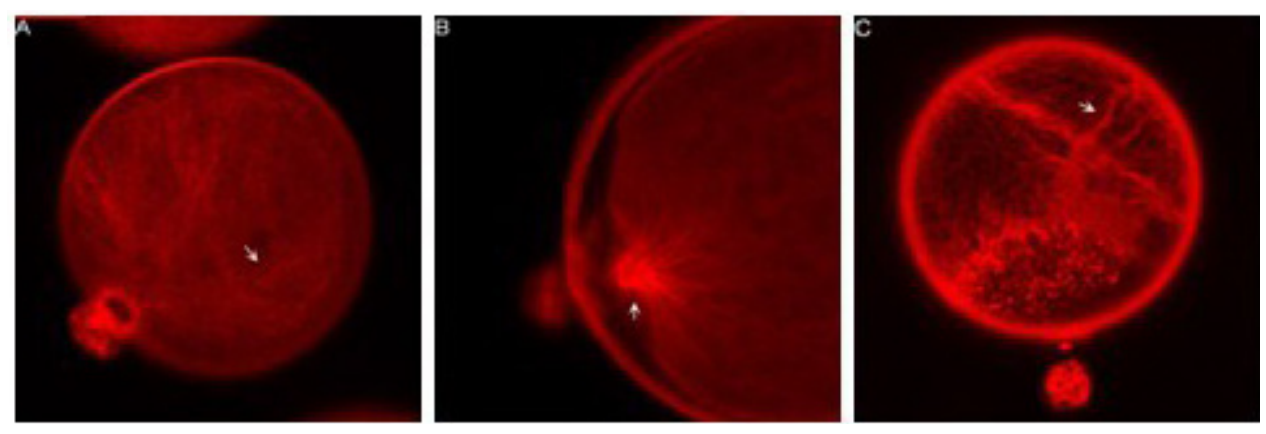

Figure 6. Confocal images of the actin filaments in pollen when the pollen tube began to elongate. A. Random actin bundles (arrow) gathered at the aperture of control pollen. B. Parallel actin bundles (arrow) extending into the emerging pollen tube in pollen treated with $5.2 \times 10^{15} \mathrm{ions} / \mathrm{cm}^{2} \mathrm{Ar}^{+}$implantation. $\mathbf{C}$. The actin filaments in pollen treated with $9.1 \times 10^{15}$ ions $/ \mathrm{cm}^{2} \mathrm{Ar}^{+}$implantation (arrow).

\section{Effects of $\mathrm{Ar}^{+}$implantation on the distribution of the actin cytoskeleton in pollen tube}

After pollen germination in vitro for $60 \mathrm{~min}$, the distribution of actin filaments in pollen tubes was observed. As shown in Figure 7B, the actin cytoskeleton in control pollen tubes formed long and parallel bundles along the shank of the pollen tubes. Figure 7D shows an abnormal pollen tube, which was elongated from $5.2 \times 10^{15}$ ions/ $\mathrm{cm}^{2} \mathrm{Ar}^{+}$implantation-treated pollen. In the shank of the tube, actin filaments are also organized into bundles arranged in a longitudinal or a helical pattern throughout the cytoplasm (Figure 7E, white arrows). The results show that the ion implantation on pollen did not cause variation of the regular pattern of actin filaments of pollen tubes.

In addition, some discontinuous actin bundles were observed in the treated pollen tube (Figure 7E, yellow arrows). Li et al. (2008) believed that those actin bundles were the fragmented actin filaments that were disrupted by ion implantation treatment, but we found that such structure also existed in the control pollen tube (Figure 7C), and those short actin bundles called "fusiform bodies" had been reported in Hosta caerulea Tratt pollen tubes, which may represent precursors of actin filaments in the pollen tube (Zhu et al., 1991). 

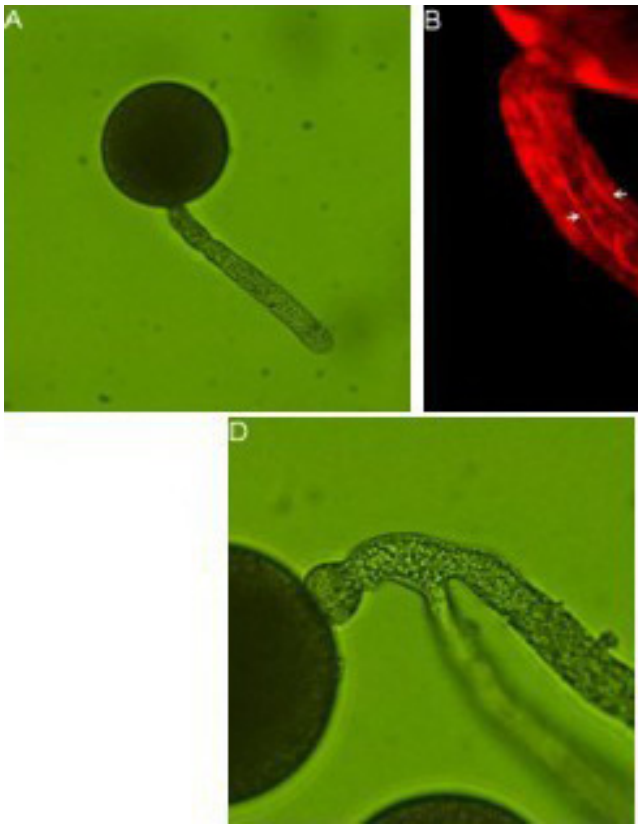
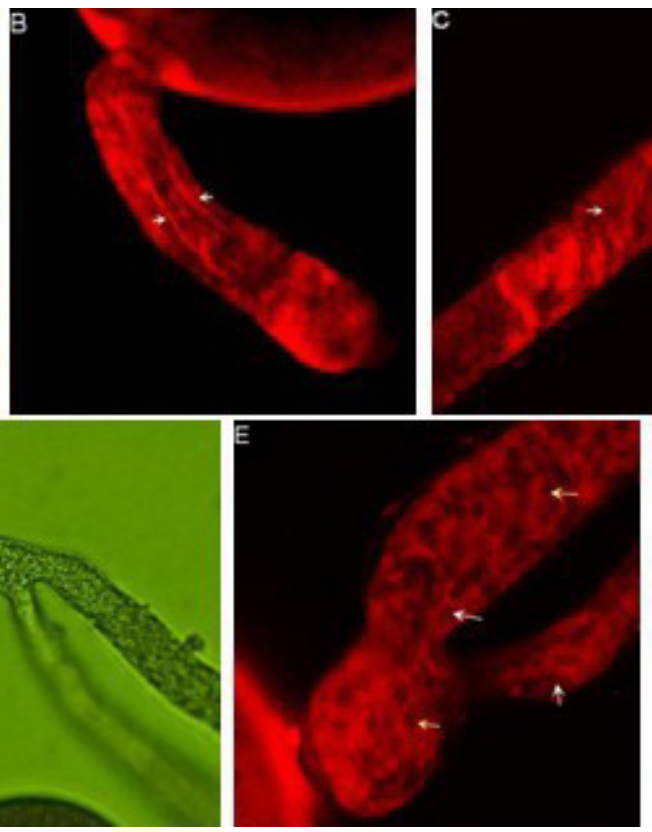

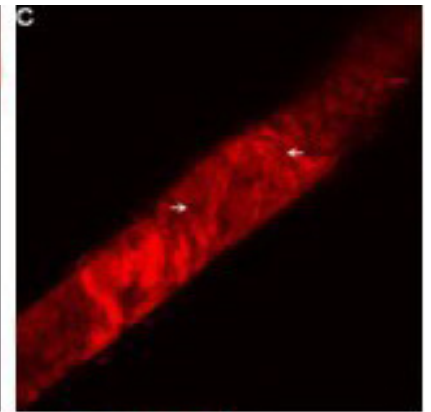

Figure 7. Confocal images of the actin cytoskeleton organization in pollen tube of maize pollen treated with ion implantation. A. Control pollen tube. B. Distribution of the actin cytoskeleton in control pollen tube (arrows: long and parallel actin bundles). C. Short and discontinuous actin bundles (arrows) in control pollen tube. D. An aberrant pollen tube following ion implantation. E. Distribution of the actin cytoskeleton in aberrant pollen tube (white arrows: long and parallel actin bundles along the shank of the pollen tube; yellow arrows: short and discontinuous actin bundles.

\section{DISCUSSION}

Physiological and genetic variations can result from implanting low-energy ions into organisms due to the electronic, energetic and qualitative effects of ions (Yu, 2000). However, the cellular mechanism of biological effects of low-energy ion implantation is still not very clear. Pollen is a model system for the study of cell polarity and apical growth; due to its relatively simple structure and approximation to a single cell, pollen is also a good recipient material for the study of the interaction of low-energy ion beams and complex organisms at the single cell level. Our research revealed that maize pollen germination could be altered by low-energy ion implantation within a certain dose range. For instance, maize pollen germination rate increased substantially using an $\mathrm{Ar}^{+}$dose ranging from 3.9 to $6.5 \times 10^{15}$ ions $/ \mathrm{cm}^{2}$. However, ion implantation only affected the initiation of pollen germination. Germination vigor of pollen implanted by $5.2 \times 10^{15}$ ions $/ \mathrm{cm}^{2} \mathrm{Ar}^{+}$was higher than that of the control within the first 30 min after germination, but it then declined and tended to be the same as the control 60 min later. Further results indicate that $\mathrm{Ar}^{+}$implantation did not influence the elongation of the pollen tube. Cytoplasmic streaming has been shown to move rapidly and bidirectionally in both treated and the control pollen tubes in a pattern described as reverse fountain streaming. It is well known that cytoplasmic streaming moves organelles around the tube and brings the vesicles to the tip, where they fuse to produce a new cell wall and plasma membrane thereby 
elongating the tube. Inhibition of this cytoplasmic streaming system would stop pollen tube elongation. The effects of $\mathrm{Ar}^{+}$implantation on maize pollen germination could be due to its prompting or inhibiting the initiation of the pollen germination.

This process of pollen germination and pollen tube growth involves a well-regulated interaction of various cellular processes, among which the dynamic organization of the actin cytoskeleton plays a major role. The dynamic organization of actin arrays during pollen germination has already been described. The actin filaments are organized as short and thick fibers inside the mature pollen grains (Vidali et al., 2001). After hydration, there is reorganization of actin filaments from a cross-linked thin filament network (Staiger and Franklin-Tong, 2003). When the pollen tube elongates, the actin filaments organize into longer bundles and gradually enter the emerging tube (Cai et al., 1997). When the pollen tube grows, the actin cytoskeleton form thick bundles parallel to the pollen tubes ( $\mathrm{Li}$ et al., 2001). In our research, such dynamic organization of actin arrays occurred in both treated and control pollen grains, but the actin cytoskeleton in pollen implanted by $5.2 \times 10^{15}$ ions $/ \mathrm{cm}^{2} \mathrm{Ar}^{+}$organized much earlier than that in the control pollen, and the reorganization of the actin cytoskeleton in pollen implanted with $9.1 \times 10^{15} \mathrm{ions} / \mathrm{cm}^{2} \mathrm{Ar}^{+}$was comparatively slower than that in the control pollen. The results indicate that the changes in the dynamic organization of the actin cytoskeleton during pollen germination are consistent with the trend of variation of germination rate mentioned above (Figure 5), suggesting that the effect of $\mathrm{Ar}^{+}$ implantation on germination rate of pollen could be due to its changing the process of the dynamic assembly of the actin cytoskeleton for pollen germination. The dynamic organization of the actin arrays is essential for pollen germination, and therefore, the disruption of this polarization process would stop pollen germination. When the maize pollen grains were implanted with $\mathrm{Ar}^{+}$beams at doses ranging from 3.9 to $6.5 \times 10^{15}$ ions $/ \mathrm{cm}^{2}$, the interaction of low-energy ions and pollen stimulated the process of polymerization and rearrangement of actin polymers, thus improving pollen germination. However, with the increase in implantation dose, the dynamic organization of the actin was gradually inhibited, thereby inhibiting pollen germination.

Different mechanisms can be envisioned for the participation of the actin cytoskeleton in pollen tube elongation. The first and most parsimonious explanation is that actin bundles control cytoplasmic streaming and hence the delivery of secretory vesicles essential for growth (Wang et al., 2006; Samaj et al., 2006). Li et al. (1998) found that the microfilaments just extended to the region 10 20 $\mu \mathrm{m}$ from the pollen tube apex, while cytoplasmic streaming also changes in direction at this region. Additional support for a role of actin microfilaments in intracellular motility comes from studies using the fungal toxin cytochalasin B. The cytoplasmic streaming rate of cytochalasin-treated tobacco pollen tubes was significantly decreased, because the drug binds to the barbed end and prevents further assembly, and this presumably leads to disassembly of the actin microfilaments (Gibbon et al., 1999). Our research also showed that the ion implantation of pollen did not cause a change in the distribution of actin filaments in pollen tubes. In both treated and control pollen tubes, actin filaments are organized in bundles that are parallel or slightly helical to the tube's longitudinal axis, and these bundles serve as tracks for cytoplasmic streaming and organelle movements. Therefore, the inhibition of this actin system would stop pollen tube growth because of the interdiction of vesicle transport. Our results coincide with previous investigations that showed that cytoplasmic streaming was correlated to the distribution of actin filaments in pollen tubes, and that the effects of ion implantation were equivalent in both streaming and actin cytoskeleton.

The above results reveal the relationship between pollen germination rate and the 
dynamic organization of the actin cytoskeleton during pollen germination. However, how the dynamic organization of actin cytoskeleton is influenced by ion implantation is not yet fully understood. Recently, growing evidence has revealed that $\mathrm{Ca}^{2+}$-gradient and small GTPases (Rop/Rac) are believed to control actin dynamic organization through the various kinds of actin-binding proteins (Lazzaro et al., 2005). Huang et al. (2001) found that the implantation of low-energy nitrogen ion caused the increase of membrane potential and intracellular calcium concentration, which was believed to be an earlier step of the stimulation effect of the implantation of low-energy nitrogen ion on lily pollen germination. Their results are consistent with our hypothesis that ion implantation only affects the initiation of pollen germination. Further studies are needed to determine the mechanism of the variation in intracellular $\mathrm{Ca}^{2+}$ of pollen in low-energy ion treatment to reveal the dynamic organization of the actin cytoskeleton during pollen germination.

\section{ACKNOWLEDGMENTS}

Research supported by grants from the National Natural Science Foundation of China (\#10675002) and National High-Tech Research and Development Program (863 Program) (\#2008AA10Z408). We thank members of the Key Laboratory of Crop Biotechnology of Anhui province for assistance in conducting these experiments.

\section{REFERENCES}

Cai G, Moscatelli A and Cresti M (1997). Cytoskeletal organization and pollen tube growth. Trends Plant Sci. 2: 86-91.

Camacho L and Malho R (2003). Endo/exocytosis in the pollen tube apex is differentially regulated by $\mathrm{Ca}^{2+}$ and GTPases. J. Exp. Bot. 54: 83-92.

Cheung AY (1995). Pollen-pistil interactions in compatible pollination. Proc. Natl. Acad. Sci U. S. A. 92: 3077-3080.

Franklin-Tong VE (1999). Signaling and the modulation of pollen tube growth. Plant Cell 11: 727-738.

Franklin-Tong VE, Hackett G and Hepler PK (1997). Ratio-imaging of $\mathrm{Ca}^{2+\mathrm{i}}$ in the self-incompatibility response in pollen tubes of Papaver rhoeas. Plant J. 12: 1375-1386.

Gibbon BC, Kovar DR and Staiger CJ (1999). Latrunculin B has different effects on pollen germination and tube growth. Plant Cell 11: 2349-2363.

Heslop-Harrison J, Heslop-Harrison Y, Cresti M, Tiezzi A, et al. (1986). Actin during pollen germination. J. Cell Sci. 86: 1-8.

Huang Z, Yanping J, Guoli Z, Ting L, et al. (2001). Effects of nitrogen ion implantation on $\mathrm{Ca}^{2+}$ concentration and membrane potential of pollen cell. Chin. Sci. Bull. 46: 1692-1694.

Ikeda S, Nasrallah JB, Dixit R, Preiss S, et al. (1997). An aquaporin-like gene required for the Brassica self-incompatibility response. Science 276: 1564-1566.

Lazzaro MD, Cardenas L, Bhatt AP, Justus CD, et al. (2005). Calcium gradients in conifer pollen tubes; dynamic properties differ from those seen in angiosperms. J. Exp. Bot. 56: 2619-2628.

Li G, Huang Q, Yang L and Qin Q (2008). Ion implantation hampers pollen tube growth and disrupts actin cytoskeleton organization in pollen tubes of Pinus thunbergii. Plasma Sci. Technol. 10: 291-293.

Li Y, Yan LF and Xu SX (1998). Distribution of F-actin and microtubes in pollen and pollen tube of Lilium davidii. Acta Bot. Sin. 40: 890-894.

Li Y, Zee SY, Liu YM, Huang BQ, et al. (2001). Circular F-actin bundles and a G-actin gradient in pollen and pollen tubes of Lilium davidii. Planta 213: 722-730.

Lu T, Cao HM and Zhang RW (1995). Observing the effect of nitrogen ion implantation in seeds of lima bean on position annihilation. Mater. Sci. Forum 175-178: 447-448.

Mascarenhas JP (1993). Molecular mechanisms of pollen tube growth and differentiation. Plant Cell 5: 1303-1314.

Samaj J, Muller J, Beck M, Bohm N, et al. (2006). Vesicular trafficking, cytoskeleton and signalling in root hairs and pollen tubes. Trends Plant Sci. 11: 594-600.

Staiger CJ and Franklin-Tong VE (2003). The actin cytoskeleton is a target of the self-incompatibility response in Papaver rhoeas. J. Exp. Bot. 54: 103-113. 
Steer MW and Steer JM (1989). Pollen tube tip growth. New Phytol. 111: 323-358.

Taylor LP and Hepler PK (1997). Pollen germination and tube growth. Annu. Rev. Plant Physiol. Plant Mol. Biol. 48: 461-491.

Vidali L, McKenna ST and Hepler PK (2001). Actin polymerization is essential for pollen tube growth. Mol. Biol. Cell 12: 2534-2545.

Wang X, Teng Y, Wang Q, Li X, et al. (2006). Imaging of dynamic secretory vesicles in living pollen tubes of Picea meyeri using evanescent wave microscopy. Plant Physiol. 141: 1591-1603.

Wei Z, Han G, Zhou G, Li Q, et al. (1996). An important mechanism of crop breeding with ultralow energy ion injection. Acta Biophys. Sin. 12: 325.

Wheeler JM, Franklin-Tong VE and Franklin FCH (2001). The molecular and genetic basis of pollen-pistil interactions. New Phytol. 151: 565-584

Wu LF, Li H and Yu ZL (1999). The application of ion beam in life science. Acta Laser Biol. Sin. 4: 299-310.

Yang HY (1999). The role of calcium in the fertilization process in flowering plants. Acta Bot. Sin. 41: 1027-1035.

Yu ZL (1999). Interaction between low energy ion and the complicated organism. Plasma Sci. Technol. 1: 79-85.

Yu ZL (2000). Ion beam application in genetic modification. IEEE T Plasma Sci. 28: 128-132.

Yu ZL and Shao CL (1994). Dose-effect of the tyrosine sample implanted by a low energy $\mathrm{N}^{+}$ion beam. Radiant. Phys. Chem. 43: 349-351.

Zhu C, Li CG and Hu SY (1991). Visualization of actin filament patterns in pollen tubes of Hosta caerulea Tratt with a non-fixation and TRITC-phalloidin method. Acta Bot. Sin. 33: 1-6. 